Sophie Krainer

\title{
Effect of Hydroxymethylfurfural (HMF) on mortality of artificially reared honey bee larvae (Apis mellifera carnica)
}

\author{
Masterarbeit \\ zur Erlangung des akademischen Grades einer \\ Magistra \\ an der Naturwissenschaftlichen Fakultät der \\ Karl-Franzens-Universität Graz
}

Betreuer:

Univ.- Prof. Dr. phil. Karl Crailsheim

Institut für Zoologie 


\section{Acknowledgements}

First I would like to thank Dr. Ulrike Riessberger-Gallé, who enabled me to investigate this topic and who always had encouraging words and a helping hand. Also I would like to thank Dr. Robert Brodschneider, who throughout provided good advice and assistance and of course Mag. Jutta Vollmann, who supported me whenever I needed help with the hives.

Last but not least, I would like to thank my family who enabled me to do what I did and whose support and patience was endless. 


\section{Index}

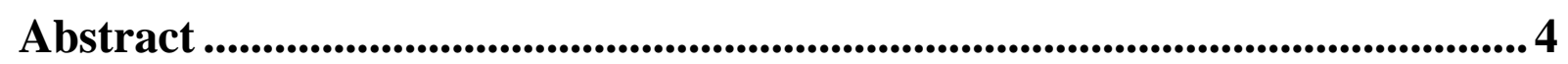

Zusammenfassung ........................................................................................................5

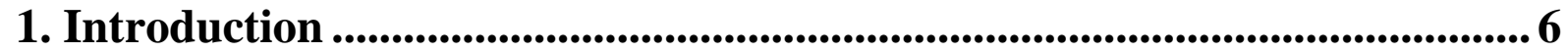

2. Materials and Methods ...............................................................................

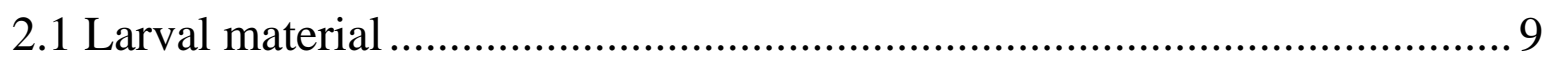

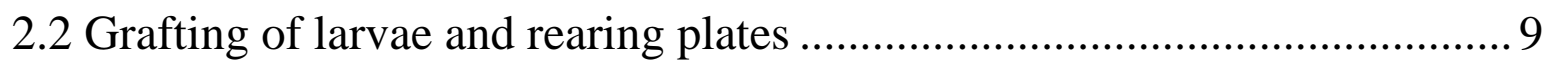

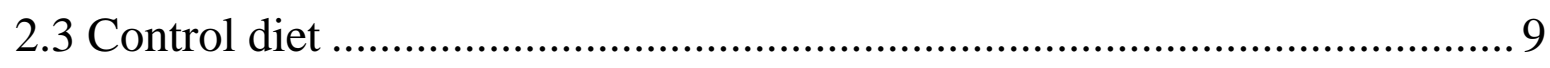

2.4 HMF- test concentration diet .............................................................. 10

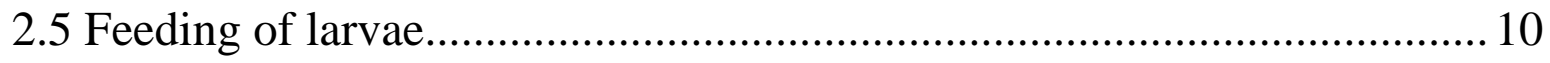

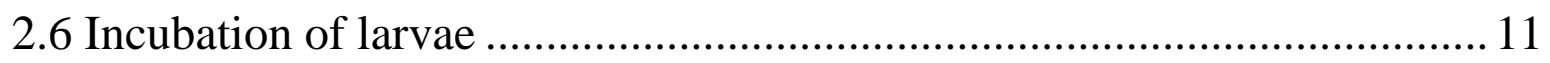

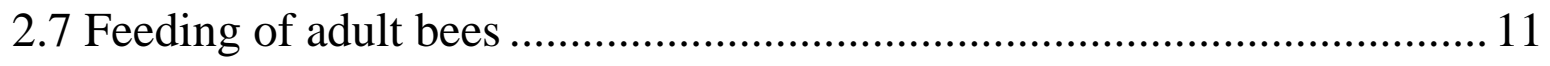

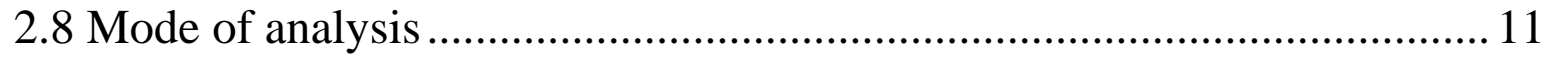

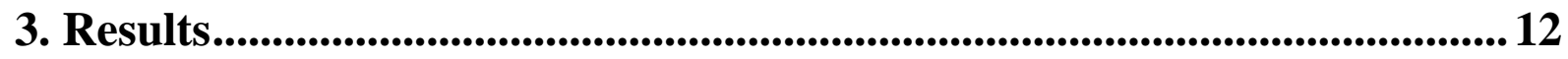

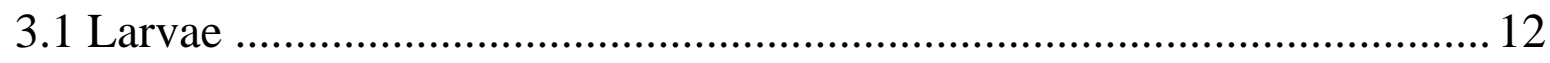

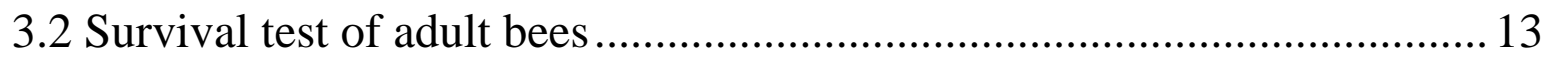

3.3 Comparison of larvae and adults ............................................................. 13

3.4 Tables and Figures ................................................................................ 14

4. Discussion .......................................................................................................................... 19

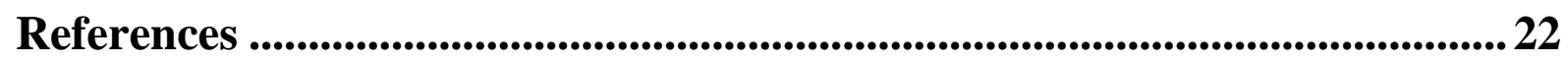




\begin{abstract}
Hydroxymethylfurfural (HMF) is a heat-formed, acid-catalyzed contaminant of sugar solutions, such as inverted sugar syrup, high fructose corn syrup (HFCS) or honey, who all find their way into honey bee feeding. As HMF was noted to be toxic to adult honey bees, we investigated toxicity of HMF towards larvae. Therefore we exposed artificially reared larvae to a chronic intoxication over 6 days, with 6 different concentrations (5, 50, 750, 5000, 7500 and 10000 ppm) of HMF. Mortality was assessed from day 2 to day 7 (d7) and day 22 (d22). Concentrations ranging from 5 to 750 ppm HMF did not show an influence on larval or pupal mortality, compared to controls ( $p>0.05$; Kaplan-Meier analysis). Concentrations of 7500 ppm or higher caused a larval mortality of 100\%. An experimental $\mathrm{LC}_{50}$ of $4280 \mathrm{ppm}(\mathrm{d} 7)$ and 2424 ppm (d22) was determined. The calculated LD Ln $_{50} 778 \mu \mathrm{g}$ HMF on d7 and 441 $\mu \mathrm{g}$ HMF on d22. Additionally we exposed adult honey bees to high concentrations of HMF and compared them to our larval results. On d7 larvae are much more sensitive against HMF than adult honey bees after 6 days of feeding. However, measured on d22, adults show a lower $\mathrm{LC}_{50}$, which indicates that they are more sensitive than larvae. Note that $\mathrm{d} 22$ larvae ingest HMF with their food only for 7 days, as pupae do not consume. Hence apparently their tolerance towards HMF increases compared to adult workers. As toxicity of HMF against honey bees is a function of time and concentration, our results indicate that HMF in supplemental food will probably not cause great brood losses. Yet sublethal effects might reduce resistance against pesticides, parasites and diseases and decrease fitness of the whole colony.
\end{abstract}

Keywords: honey bee, HMF, in vitro rearing, chronic intoxication, supplemental food 


\section{Zusammenfassung}

Hydroxymethylfurfural (HMF) ist eine chemische Verbindung, die unter dem Einfluss von Hitze und saurem pH-Wert in zuckerhaltigen Substanzen, wie Invertzuckerlösung oder Honig entsteht. Da diese Lösungen bei der Bienenfütterung eine Rolle spielen können und HMF einen toxischen Effekt auf adulte Bienen hat, wollten wir die Wirkung auf Bienenlarven untersuchen. Dazu setzten wir künstlich aufgezogene Larven einer chronischen Vergiftung mit 6 verschiedenen Konzentrationen HMF über 6 Tage aus. Die Mortalität wurde von Tag 2 bis Tag 7 (d7) und am Tag 22 (d22) protokolliert. Konzentrationen von 5 bis 750 ppm HMF zeigten dabei, verglichen mit der unbehandelten Kontrolle, keine Unterschiede in ihrer Mortalität ( $p>0.05$; Kaplan-Meier Analyse). Konzentrationen von 7500 ppm oder höher resultierten hingegen in einer Larvensterblichkeit von 100\%. Die LC 50 lag bei 4280 ppm HMF an d7 und 2424 ppm HMF an d22, die $\mathrm{LD}_{50}$ lag bei $778 \mu \mathrm{g}$ HMF an d7 und $441 \mu \mathrm{g}$ HMF an d22. Zusätzlich haben wir adulte Bienen einer hohen Konzentration HMF ausgesetzt und die Ergebnisse mit denen der Larvenversuche verglichen. An d7 waren die Larven viel empfindlicher gegenüber dem Einfluss von HMF, verglichen mit den Adulten. An d22 hingegen, waren die Adulten empfindlicher gegenüber den Larven. Man beachte, dass Larven HMF mit dem Futter nur über 6 Tage aufnehmen, da sie im Puppenstadium keine Nahrung konsumieren. Dies scheint der Grund zu sein, warum die HMF-Toleranz der Larven gegenüber den Arbeiterinnen an d22 zunimmt. Die Toxizität von HMF auf Honigbienen scheint eine Funktion aus Zeit und Konzentration zu sein, daher deuten unsere Ergebnisse darauf hin, dass HMF in zugefütterten Zuckerlösungen wahrscheinlich zu keinen großen Brutverlusten führt. Allerdings können sublethale Effekte zu einem geringeren Widerstandsvermögen gegen Pestizide, Parasiten und Krankheiten führen und in weiterer Folge die Gesundheit des gesamten Stockes beeinflussen. 


\section{Introduction}

Honey bee nutrition plays a vital part in developing and maintaining healthy and strong colonies. Next to protein, which is necessary for brood production, carbohydrates are essential, as they provide energy for all activities within the hive and during foraging. Honey bees naturally obtain carbohydrates by collecting honeydew or nectar. In times when natural sources are limited or harvesting honey has removed a colonies supply of carbohydrates, supplemental feeding by beekeepers is necessary [Haydak, 1970; Brodschneider and Crailsheim, 2010] and quite common. Usually sucrose solution, inverted sugar syrup or other syrups, such as starch syrup or high fructose corn syrup (HFCS) are used for that purpose [Jachimowicz and El Sherbiny, 1975; Le Blanc et al., 2009; Brodschneider et al., 2010; Brodschneider and Crailsheim, 2010].

Since it was found that some sugars, for example galactose, mannose and lactose are toxic to honey bees in certain concentrations [Barker and Lehner, 1976; Barker, 1977], these do not find their way into supplemental feeding.

Yet another substance that is toxic to bees can be found in syrups applied for colony nutrition: Hydroxymethylfurfural (HMF), a chemical compound, forming from carbohydrates, especially fructose, under thermal and/or acid-catalyzed decomposition. It is found in many sugar containing food products, like invert sugars, juices, jams, syrups and honey [Jachimowicz and El Sherbiny, 1975; ALabdeen Makawi et al., 2009, LeBlanc et al., 2009]. As mentioned above, some of those products are used supplemental honey bee feeding, such as inverted sugar syrup or HFCS. Sometimes even non used honey is brought back to the hive as supplemental food. As a consequence, HMF content of those products is of great interest to beekeepers. Three methods are commonly used to detect HMF in sugar solutions, which have been tested to deliver quite similar results [Bogdanov, 2002], the HPLC method [Jeuring and Kuppers, 1980; Kim and Richardson, 1992; Risner et al., 2006] and the two spectrophotometric methods of Winkler [1955] and White [1979].

Contamination of honey and different sugar solutions with HMF has been investigated very well. Le Blanc et al. [2009] investigated HMF content of commercially available HFCS of different brands and found concentrations ranging between 3.1 and 28.7 ppm HMF for fresh syrups. They also analyzed formation of HMF in several samples of HFCS under different temperature conditions. Results showed that constant high temperatures can cause high levels of HMF, especially in acid-catalyzed HFCS. For example, a temperature of $49^{\circ} \mathrm{C}$ can cause a formation of more than 200 ppm HMF over a period of 36 days. Some samples exposed to 
$69^{\circ} \mathrm{C}$ for the same time, obtained HMF values higher than 30.000 ppm HMF. Ruiz-Matute et al. [2010] found HMF concentrations ranging from 26.91 to 102.31 ppm in samples of HFCS. Analysed samples supplied by manufacturers showed lower HMF-levels than those supplied by beekeepers, suggesting the former have been fresh and properly shelved. The syrupsamples containing the highest amounts of HMF were stored in metal tanks, standing outside unprotected from sunlight and hence could be exposed to permanent high temperatures, especially during summer months. Van der Zee and Pisa [2010] investigated HMF content of (Fructo-Bee $^{\circledR}$ ) inverted sugar solution. Samples were leftovers of winter feeding, provided by beekeepers that had suffered of high colony losses over the winter. They found HMF values up to $466.2 \mathrm{ppm}$ in samples with a "best before” date nearly 4 years after analysis.

Fresh honey usually contains no or low amounts of HMF [Bogdanov et al., 1999]. Due to this fact, HMF content has become one of the most important criteria in honey quality evaluation [White, 1994]. On the European market honey must contain less than 40 ppm HMF when placed on the market [Council Directive relating to honey, 2002]. Due to improper storage, honey, which naturally shows an average $\mathrm{pH}$ of 3.91 for floral and 4.45 for honeydew honey [Doner, 1977], can develop a high amount of HMF during storage, just like HFCS, which is quite similar in sugar composition and ph-value [Ruiz-Matute et al., 2010]. Tosi et al. [2001] investigated the effect of short term heating on HMF concentration of different honey samples and found that an exposure of 60 seconds at $100^{\circ} \mathrm{C}$ caused an increase from 3.9 to $10.1 \mathrm{ppm}$ HMF. Karabournioti and Zervalaki [2001] exposed honey of several botanic origins to different temperatures for 24 hours. They found HMF concentrations ranging from 1.9529.20, 2.25-32.60, 4.35-39 ppm HMF, at temperatures of 35,45 and $55^{\circ} \mathrm{C}$, respectively. Exposure to $75^{\circ} \mathrm{C}$ for 24 hours resulted in HMF concentrations from 43.40 to 226.35 ppm HMF. ALabdeen Makawi et al. [2009] found high HMF concentrations in Sudan honey samples (up to $922 \mathrm{ppm}$ ), stored for several years.

Bailey [1966] already discovered, that honey stored for many years and therefore containing high amounts of HMF, caused increasing mortality to bees, compared to fresh honey. He also observed that HMF caused gut ulceration resulting in dysentery. The toxicity of HMF on adult workers was, among others, investigated by Jachimowicz and El Sherbiny [1975]. They showed that a level of 150 ppm HMF, solved in a mimicked inverted sugar solution consisting of glucose, fructose and sucrose, caused a significantly increased mortality within 20 days in caged bees. A concentration of 30 ppm HMF however, did cause no significant difference in mortality of adults, approving the European Union Council Directive relating to honey [2002]. Le Blanc et al. [2009], feeding HMF contaminated HFCS, reported results very close 
to those of Jachimowitz and El Sherbiny and found that over a period of 26 days, 250 ppm HMF caused mortality significantly higher than any of the other (lower) treatment groups.

These studies indicate that the toxicity of HMF on adult workers is well investigated. Yet little is known about toxicity of HMF to larvae. Larval food, which is next to protein and lipids rich in carbohydrates, is produced by nurse bees after ingesting carbohydrates and pollen [Haydak, 1970; Brouwers et al., 1987; Kunert and Crailsheim, 1987]. It is likely, that HMF finds its way into larval nutrition when nurse bees consume contaminated honey or sugar syrup such as HFCS, but larval susceptibility has not been studied yet.

To test effects of chemicals, such as insecticides, on honey bee brood, different methods have been published over the years. Oomen [1992] described an in-hive method, which is an official recommended method for testing insect growth regulators, according to the guidelines of the European Union [OEPP/EPPO, 2001 and 2003]. Yet, this method may not be easily reproducible, due to changing environmental conditions and the influence of adult workers. Besides, the in-hive test supplies no individual quantitative data, as no one can determine, how much of the tested substance is ingested by larvae [Aupinel et. al., 2007]. Methods developed for risk assessment towards honey bee larvae in the laboratory [Rembold and Lackner 1981; Vandenberg and Shimanuki, 1987; Peng et al., 1992; Aupinel et al., 2005; Medrzycki et al., 2010; Hendriksma et al., 2011] allow the precise determination of lethal concentration and/or dose. The quality of artificially reared bees has been investigated by Brodschneider et al. [2009] by comparing flight performance of in vitro reared larvae and their natural sisters. Results indicate that artificially reared bees at the natural age of flight show a similar performance as those reared in the hive.

We investigated the effect of chronic intoxication with HMF on mortality of artificially reared honey bee brood. Further we wanted to know, whether larvae are more sensitive to HMF than adults. If that is the case, supplemental feeding with HMF contaminated food could influence larval mortality and cause brood-losses as well as sublethal damage. 


\section{Materials and Methods}

\subsection{Larval material}

All larvae used in the following tests, originated from three hives of Apis mellifera carnica, located at the Department of Zoology, Karl-Franzens-Universität, Graz.

To obtain $1^{\text {st }}$ instar larvae, the queen was caged on an empty comb in a queen excluder cage in the colony for 36 hours, then was released and set back to the hive. Worker bees were able to move in and out of the cage without limitation all the time. Four days after caging, the comb was taken to the laboratory, where grafting of larvae took place on day 1 with 5-10 old larvae.

\subsection{Grafting of larvae and rearing plates}

To rear larvae under laboratory conditions, we adopted a method close to Aupinel [2005]. 48-well culture plates were prepared to provide a convenient replacement for the natural comb. Pieces of dental roll were placed at the bottom of each well. $500 \mu \mathrm{l}$ of $15 \%$ glycerol solution per well were used to damp the dental roll. A common plastic queen starter cup was placed at the top of the dental roll. Prior to this, the cup has been sterilized by a solution of Milton Sterilising Tablets (Milton), rinsed with autoclaved, deionised water and dried. After preparation, the entire plate was put under UV-light over night for sterilisation. Before grafting, each cup was supplied with $10 \mu \mathrm{l}$ of diet for the first day.

First instar larvae were transferred from the comb to the queen starter cup, by using a small paintbrush. To avoid microbial contamination, brushes for grafting were sterilized with ethanol (96\%) and rinsed with autoclaved, deionised water.

\subsection{Control diet}

Three basic diets were fed, diet A, B and C [Aupinel et al., 2005]. On day 1 and 2, diet A was given, on day 3 diet $B$ and from day 4 to day 6 larvae received diet $C$. The amount $(\mu l)$ per larva/day was $10,10,20,40,40$, and 50, respectively. This resulted in a total amount of $170 \mu \mathrm{l}$ of food per larvae. Each diet consisted of 50\% royal jelly and 50\% aqueous sugar solution (w/w). The composition of these 3 sugar solutions (su) changed from $12 \%$ fructose, $12 \%$ glucose, $2 \%$ yeast extract (sugar solution A), to 15\% fructose, 15\% glucose, 3\% yeast extract (sugar solution B) to 18\% fructose, 18\% glucose, $4 \%$ yeast extract (sugar solution C). 
Solid components were weighed, solved in sterilised, deonised water and filled up to a certain volume (w/v). Basic diet without HMF was fed to control group.

Royal jelly used in these experiments was purchased at a local store for beekeeper supply in $50 \mathrm{~g}$ portions and freeze stored at $-70^{\circ} \mathrm{C}$. Defrosted jelly was kept refrigerated at $4{ }^{\circ} \mathrm{C}$ and used up within a week.

\subsection{HMF- test concentration diet}

Food for test groups was supplied with HMF purchased from SAFC in the following way: a highly concentrated HMF stock solution (st) of 40.000 ppm was prepared and a double concentrated (A, B or C)-sugar solution was used for preparation and diluted afterwards according to Tab. I.

For one plate (=48 larvae) $1000 \mathrm{mg}$ of diet A, $2000 \mathrm{mg}$ of diet B and $3000 \mathrm{mg}$ of diet C, depending on testing day, were prepared freshly. Excess of food was dumped if not used. To calculate the amounts of all ingredients for test diet preparation, Tab. 1 was used.

To find a suitable concentration range, preliminary tests were carried out. The final test concentrations (tc) were set at 5, 50, 750, 5000, 7500 and 10.000 ppm HMF to allow estimation of a $\mathrm{LC}_{50}$ within 7 days of larval development. As we investigated chronic intoxication, HMF was given to test groups with the food from day 1 (=day of grafting) to day 6. Whereas the quantum and composition (diet A, B, C) of applied food changed over the period of feeding, HMF concentration remained constant all the time.

\subsection{Feeding of larvae}

Before feeding, each larva was checked for its health status. A larva was defined as healthy, when it was plump and shiny and movements of breathing pores could be observed under the binocular. A Larva that did not show any of these characteristics was considered as dead and removed for reasons of sanitation.

Larvae were fed over a period of 6 days. Feeding took place under a laminar flow to keep risk of contamination at a minimum. Amount and composition of diet changed over the feeding period, as described by Aupinel et al. [2005]. The prewarmed food was supplied once a day, at the same time as grafting on day 1 took place. 


\subsection{Incubation of larvae}

Larvae were transferred into an incubator with a constant temperature of $34.5^{\circ} \mathrm{C}$. To maintain humidity, rearing plates were placed in hermetic Plexiglass dessicators. Saturated solution of $\mathrm{K}_{2} \mathrm{SO}_{4}$ was used to keep humidity at $96 \%$ for the first 7 days. To prevent stretching larvae from dropping out, queen cups were lowered by removing the dental rolls on day 8. On the same day, plates were transferred to a dessicator supplied with saturated solution of $\mathrm{NaCl}$, which kept humidity at approximately $80 \%$. To avoid deformation of emerging adults plates were put into an upright position on day 12 [Brodschneider et al., 2009]. A thin, perforated layer of wax prevented pupae from falling out of the plate and enabled eclosion of adults.

A special plastic lid, fitting on the edges of the 48-well plates and serving as a spacer, with holes for air ventilation, allowed bees to emerge, but kept them at the plate and avoided mixing with bees from other testing groups. An Eppendorf tube (2ml) with holes at the tip was filled with honey solution (50\%) and placed inside this box, to provide food for emerging bees.

Mortality of each group was noted from day 2 (d2) to day 7 (d7) and on day 22 (d22), when bees had eclosed.

\subsection{Feeding of adult bees}

To validate the effect of the purchased HMF adult bees were fed with $50 \%$ sucrose solution, containing HMF in three concentrations: 2000, 4000 and 8000 ppm. The control group received pure sucrose solution. We chose sucrose, as caged bees survive best on sucrose syrup [Barker and Lehner, 1978]. Newly emerged worker bees (younger than 24 hours), originating from the same three hives as larvae, were transferred to cages slightly modified after Evans et al. [2009]. Food was provided ad libitum in Eppendorf tubes with small holes. Mortality of each group was noted daily until d22. Three replicates of 100 bees each were run per treatment group, which resulted in a total number of 1200 bees.

\subsection{Mode of analysis}

We performed 51 trials with 48 larvae per replicate. To calculate the median lethal concentration $\left(\mathrm{LC}_{50}\right)$ the linear regression of dose-response curves for each day was calculated using MS-Excel (Microsoft). The obtained $\mathrm{LC}_{50}$ was used to calculate the median lethal dose $\left(\mathrm{LD}_{50}\right)$, assuming that the total amount of $170 \mu \mathrm{l}$ diet was consumed by each larva. This is legitimized as those larvae that had not ingested all of the provided food by d7 were observed 
to die during pupal stage. To compare results to those of other studies dealing with toxicity of chemicals on larvae, we decided to focus on mortality on $\mathrm{d} 7$ and $\mathrm{d} 22$. Survival analysis was performed with MedCalc (MedCalc Software), using the Kaplan-Meier analysis.

\section{Results}

\subsection{Larvae}

On d7, 24 hours after last administration of food, mortality of test groups receiving concentrations 5, 50 or 750 ppm HMF was noted as 6.9\% ( \pm 1.5 se; $n=288), 10.1 \%( \pm 1.77$ se; $\mathrm{n}=288)$ and $6.8 \%( \pm 1.38 \mathrm{se} ; \mathrm{n}=336)$, respectively (Fig. 1). A test concentration of $5000 \mathrm{ppm}$ HMF resulted in mortality of $52.4 \%( \pm 2.72$ se; $n=336)$. The two highest of tested concentrations, $7500(n=288)$ and $10.000(n=336)$ ppm HMF both resulted in a mortality of $100 \%$ on $\mathrm{d} 7$ (Fig. 1). The non-treated control group showed a mean mortality of $9 \%( \pm 1.19$ se, $n=576)$ calculated from grafting until $d 7$. The three lowest tested concentrations (5, 50, $750 \mathrm{ppm}$ ) did not show a significant effect on larval mortality, compared to control group (p>0.05; Kaplan-Meier analysis). However, significant different mortality could be detected between control group and the 5.000 ppm, 7.500 ppm and 10.000 ppm HMF treatment group ( $\mathrm{p}<0.0001$; Kaplan-Meier analysis). Differences ( $\mathrm{p}<0.05$; Kaplan-Meier analysis) in mortality between the 5.000 and 10.000 ppm treatment group and control group were already spotted on $\mathrm{d} 2$, whereas the $7.500 \mathrm{ppm}$ treatment group showed a significant difference firstly on $\mathrm{d} 3$ (Fig.1).

Larval mortalities until d22 for concentrations 5, 50 and 750ppm HMF were 26.4\% $( \pm 2.60$ se), $30.2 \%$ ( $\pm 0.0271 \mathrm{se})$ and $32.1 \%$ ( \pm 0.0255 se), respectively. Control group mortality was noted at 28.1 ( \pm 0.0187 se) \%. No significant difference was detected between mortality of control and the three lowest test groups ( $>>0.05$, Kaplan-Meier analysis). The treatment group receiving 5000ppm HMF showed a mortality of $87.5 \%$ ( \pm 0.0180 se) on day 22 (see Fig.1), which was significant higher than that controls $(\mathrm{p}<0.05$; Kaplan-Meier analysis).

A linear regression of $y=0.0101 x+6.7702$ for $\mathrm{d} 7$ and $\mathrm{y}=0.0083 \mathrm{x}+29.878$ for $\mathrm{d} 22$ was calculated (see Tab. II), whereby $\mathrm{y}=$ mortality and $\mathrm{x}=$ ppm HMF. Linear regressions and coefficients of determination for $\mathrm{d} 2$ to $\mathrm{d} 7$ as well as $\mathrm{d} 22$ are presented in Tab. II.

The estimated $\mathrm{LC}_{50}$ of HMF strongly depends on the duration of experiments (Tab. II). For example, a $\mathrm{LC}_{50}$ of 4280 ppm (d7) and 2424 ppm (d22) HMF was determined. According to a total quantity of $170 \mu \mathrm{l}$ of food per larva and the calculated $L_{50}$, we assessed an $L_{50}$ for a 
chronic intoxication over 6 days. This calculated $\mathrm{LD}_{50}$ was $778 \mu \mathrm{g}$ HMF on d7 and $441 \mu \mathrm{g}$ HMF on d22.

\subsection{Survival test of adult bees}

Measured on d7 adult worker control group and 2000 ppm HMF test group both showed a mortality of $0.7 \%$, with a standard error of \pm 0.470 , each (Fig. 2). The 4000 ppm HMF test group evinced a mortality of $3 \%$ ( \pm 0.985 se) and treatment group receiving 8000 ppm HMF showed a mortality of $5 \%( \pm 1.26 \mathrm{se}$ ) (Fig. 2). At the end of the test on d22, mortality of untreated control group was $6.7 \%( \pm 1.44$ se), whereas all bees feed with 4000 ppm HMF in sucrose solution were dead on d20 (Fig. 2). Treated bees fed with 8000 ppm HMF showed a mortality of $100 \%$ on $\mathrm{d} 15$. Within the test group receiving 2000 ppm HMF, a mortality of $67 \%$ ( \pm 2.71 se) was noted on d22 (Fig. 2).

Caged adults of different treatment groups did not show differences in mortality during the first 5 days. On d6 mortality of the 4000 ppm HMF treatment group started to be significantly higher ( $\mathrm{p}=0.011$, Kaplan-Meier analysis) than that of control group. Mortality of workers fed with 8000 ppm HMF started to become significantly higher than that of controls on $\mathrm{d} 7$ ( $\mathrm{p}=0.0014$, Kaplan-Meier analysis). The treatment group that received $2000 \mathrm{ppm}$ HMF showed a significant different mortality, compared to control, firstly on d16 ( $\mathrm{p}=0.0022$, Kaplan-Meier analysis).

Mortality data obtained throughout the whole test period where used to determine the linear regression, a $\mathrm{LC}_{50}$ and the coefficient of determination $\left(\mathrm{R}^{2}\right)$, same as for larvae. Data are presented in Tab. II. For adult workers we determined a LC $_{50}$ of 82778 ppm HMF for d7 and a $\mathrm{LC}_{50}$ of 1843 ppm HMF on $\mathrm{d} 22$, no $\mathrm{LD}_{50}$ was calculated because individual consumption is unknown.

\subsection{Comparison of larvae and adults}

Data of linear regression, coefficient of determination and $\mathrm{LC}_{50}$ for both, larvae and adults are shown in Tab. II. The $\mathrm{R}^{2}$ indicates that reliability of shown values is dependent on the duration of intoxication. Compared on $d 7$, larvae show a much higher sensitivity on intoxication with HMF than adults. Until d22 however, workers are slightly more sensitive than larvae.

Chosen dose-response curves of larvae and adults are shown in Fig. 3. Mortality of larvae dramatically increases between $\mathrm{d} 2$ and $\mathrm{d} 4$ (Fig. 3. a), whereas that of workers increases on $\mathrm{d} 8$ 
(Fig. 3. b). As larval and adult mortality differ from $\mathrm{d} 3$ to d7, with a mortality indicating that larvae are more sensitive to HMF before d7 (see Fig. 3 c and d), mortality of adults and larvae converge until d22 (see Fig. $3 \mathrm{a}+\mathrm{b}$ ).

\subsection{Tables and Figures}

Table I: Preparation of the three different test-diets according to different HMF concentrations: amount of sugar solution (su) and royal jelly (RJ) is constant in different concentrations of HMF test food, whilst quantity of stock solution (st) and aqua dest. change within concentration range. Stock solution contains 40.000 ppm HMF (=stock concentration, sc). Test concentrations (tc) were 5, 50, 750, 5000, 7500 and 10.000 ppm HMF.

\begin{tabular}{|c|c|c|c|c|c|c|}
\hline day & diet & $\begin{array}{c}\text { stock } \\
\text { solution (st) } \\
{[\mu l]}\end{array}$ & $\begin{array}{c}\text { royal } \\
\text { jelly }(R J) \\
{[\mathrm{mg}]}\end{array}$ & $\begin{array}{c}\text { sugar } \\
\text { solution (su) } \\
\text { [mg] }\end{array}$ & $\begin{array}{c}\text { aqua dest. } \\
{[\mu \mathrm{l}]}\end{array}$ & $\begin{array}{c}\text { diet per } \\
\text { plate [mg] }\end{array}$ \\
\hline 1,2 & A & $1000 /(\mathrm{sc} / \mathrm{tc})$ & 500 & 250 & $1000-(\mathrm{st}+\mathrm{RJ}+\mathrm{su})$ & 1000 \\
\hline 3 & B & $2000 /(\mathrm{sc} / \mathrm{tc})$ & 1000 & 500 & 2000-(st+RJ+su) & 2000 \\
\hline $4,5,6$ & C & $3000 /(\mathrm{sc} / \mathrm{tc})$ & 1500 & 750 & 3000-(st+RJ+su) & 3000 \\
\hline
\end{tabular}


Table II: Linear regression (y), coefficient of determination $\left(\mathrm{R}^{2}\right)$ and $\mathrm{LC}_{50}$ of larvae and adult bees from d2 to day 22. As day 1 was day of grafting and first application of HMF, inquiry of mortality started on day 2. To minimize the influence of handling on development of pupae, larval mortality was not assessed from d8 to d22.

\begin{tabular}{|c|c|c|c|c|c|c|}
\hline \multirow[b]{2}{*}{ day } & \multicolumn{3}{|c|}{ larvae } & \multicolumn{3}{|c|}{ adults } \\
\hline & linear regression & $\mathbf{R}^{2}$ & $\mathbf{L C}_{50}$ & linear regression & $\mathbf{R}^{2}$ & $\mathbf{L C}_{50}$ \\
\hline d2 & $y=0.0008 x+1.7761$ & 0.2456 & 60280 & $y=0.0001 x+0.0667$ & 0.2136 & 499333 \\
\hline d3 & $y=0.0053 x+0.9472$ & 0.6882 & 9255 & $y=0.0001 x+0.0667$ & 0.2136 & 499333 \\
\hline d4 & $y=0.0088 x+0.6175$ & 0.8719 & 5612 & $y=0.0001 x+0.0667$ & 0.2136 & 499333 \\
\hline d5 & $y=0.0098 x+1.5034$ & 0.8905 & 4949 & $y=0.0001 x+0.2$ & 0.28 & 498000 \\
\hline d6 & $y=0.0101 x+3.6835$ & 0.9171 & 4586 & $y=0.0002 x+0.6667$ & 0.1203 & 246667 \\
\hline d7 & $y=0.0101 x+6.7702$ & 0.9358 & 4280 & $y=0.0006 x+0.3333$ & 0.467 & 82778 \\
\hline d8 & - & - & - & $y=0.0017 x-1.2$ & 0.8609 & 30118 \\
\hline d9 & - & - & - & $y=0.0046 x-5.6$ & 0.8117 & 12087 \\
\hline d10 & - & - & - & $y=0.0081 x-11$ & 0.7799 & 7531 \\
\hline d11 & - & - & - & $y=0.0103 x-13.533$ & 0.8221 & 6168 \\
\hline d12 & - & - & - & $y=0.0119 x-14.133$ & 0.8667 & 5389 \\
\hline d13 & - & - & - & $y=0.0129 x-12.467$ & 0.917 & 4842 \\
\hline d14 & - & - & - & $y=0.0133 x-8.4$ & 0.9264 & 4391 \\
\hline d15 & - & - & - & $y=0.0136 x-3.4667$ & 0.8733 & 3931 \\
\hline d16 & - & - & - & $y=0.0136 x+1.3333$ & 0.8129 & 3578 \\
\hline d17 & - & - & - & $y=0.0132 x+7.4$ & 0.7682 & 3227 \\
\hline d18 & - & - & - & $y=0.0126 x+13.733$ & 0.7688 & 2878 \\
\hline d19 & - & - & - & $y=0.0119 x+20.2$ & 0.7448 & 2504 \\
\hline d20 & - & - & - & $y=0.0113 x+25.8$ & 0.6895 & 2142 \\
\hline d21 & - & - & - & $y=0.0109 x+29.2$ & 0.6546 & 1908 \\
\hline d22 & $y=0.0083 x+29.878$ & 0.7858 & 2424 & $y=0.0108 x+30.099$ & 0.6510 & 1843 \\
\hline
\end{tabular}




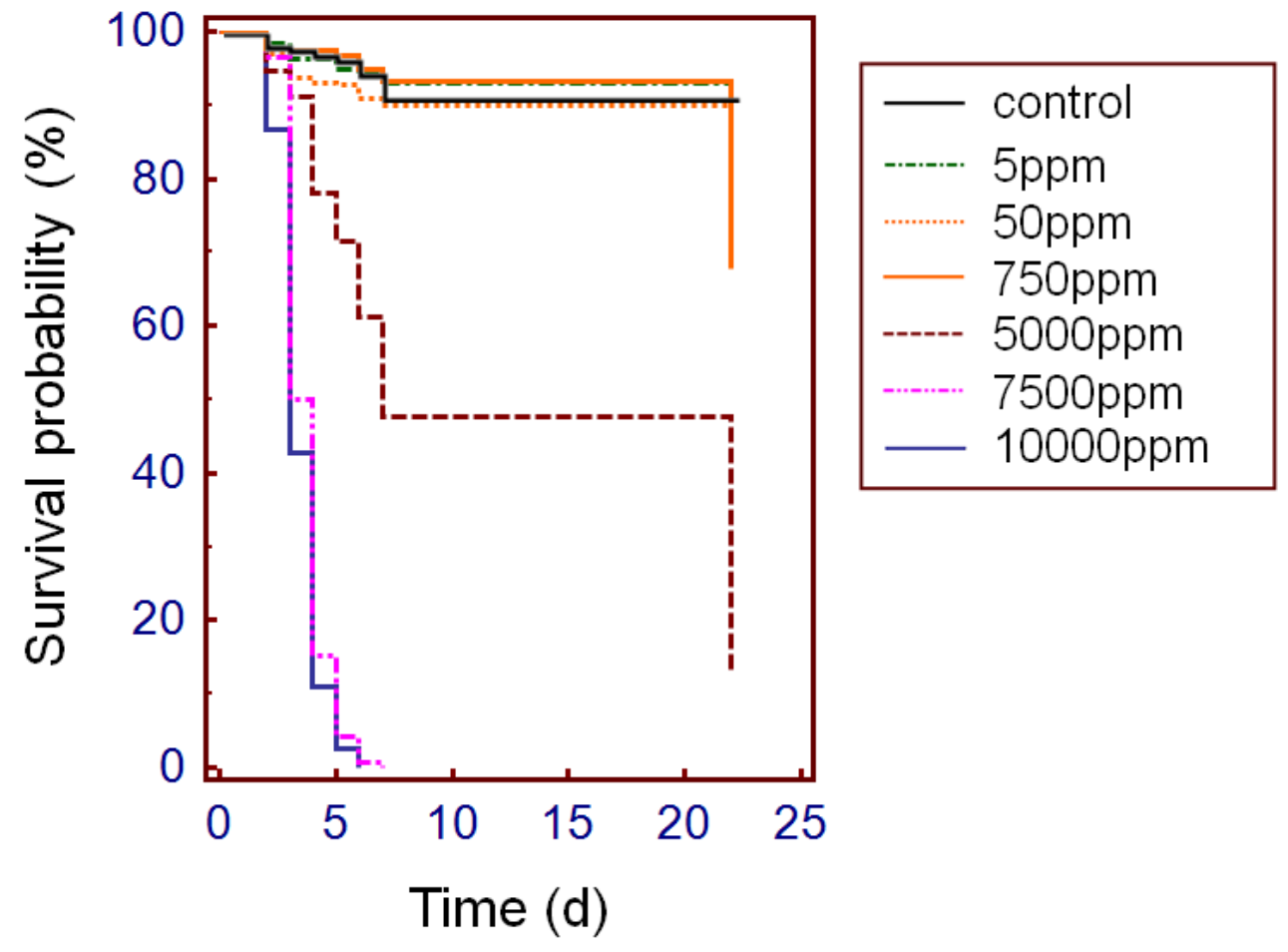

Figure 1. Survival probability for six different concentrations of HMF and control group, noted from d1 to d7 and on d22. $\mathrm{n}=288$ (groups 5, 50, 7500 ppm) each, n=336 (groups 750, 5000, 10.000 ppm) each and $n=576$ for control group. 


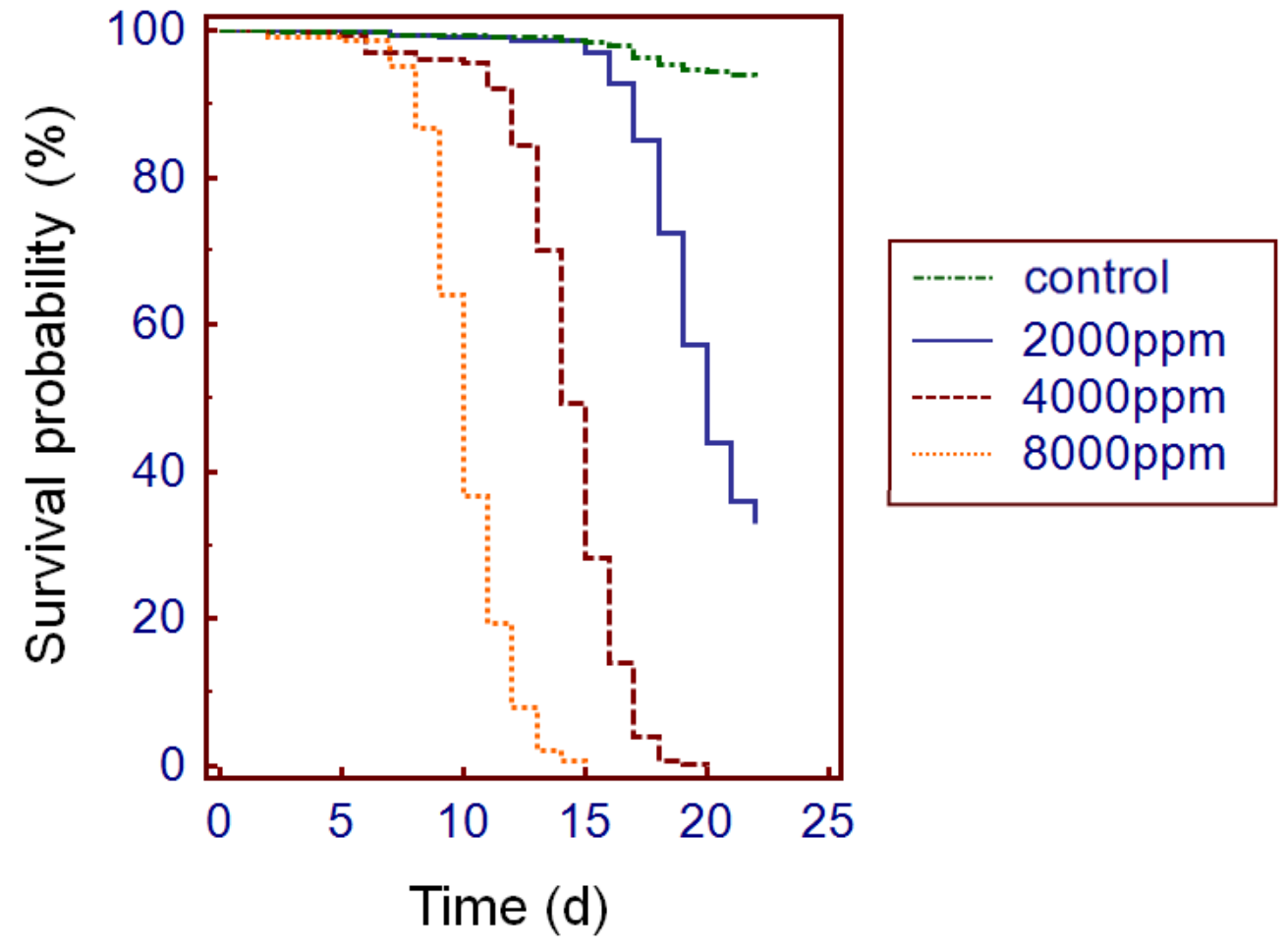

Figure 2. Survival probability from d1 to d22 for caged bees treated with three different concentrations of HMF and non treated control group. $\mathrm{n}=3$ replicates each, with 100 bees per replicate. 


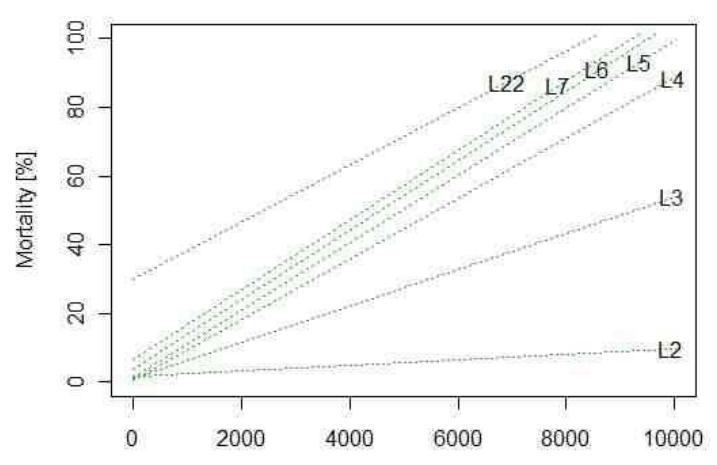

a)

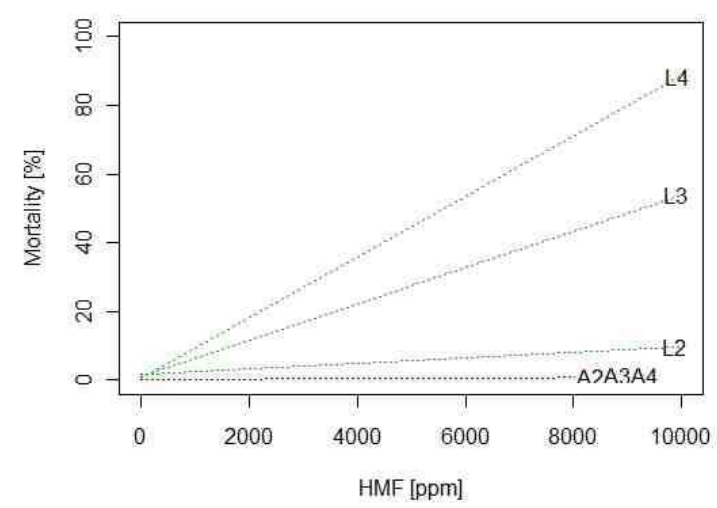

c)

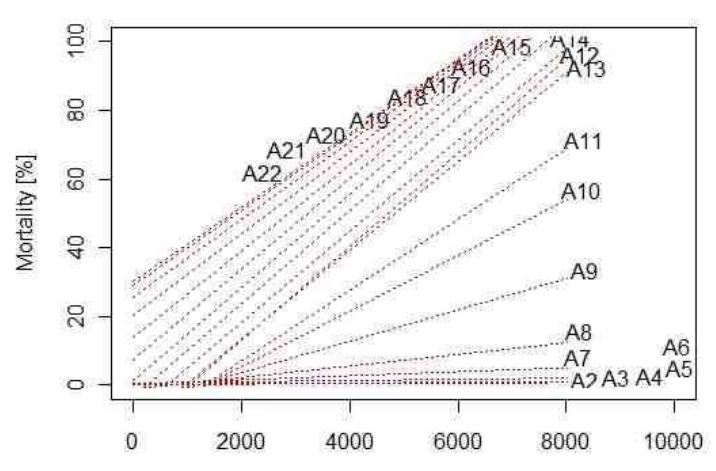

b)

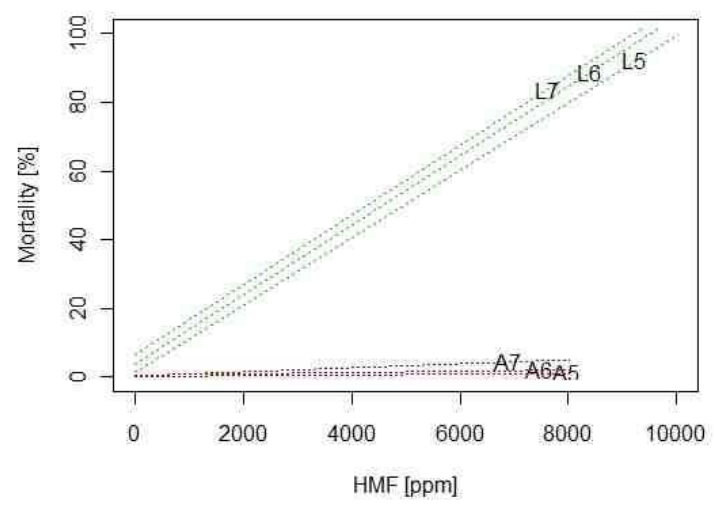

d)

Figure 3. Dose response curves of larvae and adults, treated with different HMF concentrations. A letters indicate adults, L letters larvae. a) shows data of larvae only from d2 to d7 and $\mathrm{d} 22$, b) shows data of adults only from $\mathrm{d} 2$ to $\mathrm{d} 22$, c) shows data of adults and larvae from $\mathrm{d} 2$ to $\mathrm{d} 4 \mathrm{and}$ d) shows data of larvae and adults from d5 to d7. 


\section{Discussion}

This is the first study of toxicity of HMF on honey bee larvae, using the in vitro standardized feeding method protocol by Aupinel et al. [2005, 2007]. Larvae treated with concentrations of 750 ppm HMF or lower, didn't show increased mortality, compared to control. In our experimental setup below 5000 ppm HMF no difference can be detected within 7 days of larval life. Larval mortality of control group was below $10 \%$ on $\mathrm{d} 7$, with no larvae replaced after grafting, as chronic intoxication started on d1. An estimated $\mathrm{LC}_{50}$ of 4280 on $\mathrm{d} 7$ and 2424 ppm HMF on d22 for larvae indicates that they are more resistant to HMF than we had expected, referring to HMF related data for caged workers [Jachimowicz and El Sherbiny, 1975, Le Blanc, 2009].

Little is known about the physiological effects of HMF on larvae or its metabolism. We do not know whether it causes gut ulceration as it is suggested in adult bees [Bailey, 1966] but similar mechanisms might be possible. HMF fed to larvae might be exuded with faeces or accumulated and stored in larval body. Furthermore, possible damage could be repaired during metamorphosis. Comparing our current results to published data of chronic intoxication with the pesticide dimethoate [Aupinel et al., 2007], which caused a $\mathrm{LC}_{50}$ lower than $10 \mathrm{ppm}$, we found that HMF is much less toxic after 6 days of oral exposure.

As royal jelly contains 7-18 \% carbohydrates [Sabatini et al., 2009] one might consider that actual HMF content of our food might be higher than the stated concentrations. Yet we neglect this risk, as we purchased fresh royal jelly and storage temperature could not have induced formation of HMF. As fresh honey contains no or low amounts of HMF [Bogdanov et al.; 1999] its content in fresh royal jelly should be negligible.

Our current results for intoxication of adult workers can be compared to those of caged bees in preceding studies (Jachimowicz and El Sherbiny, 1975, Le Blanc, 2009), with the limitation that they used different sugar solutions. We used sucrose solution due to proven best longevity of adult bees [Barker and Lehner, 1978], whereas Jachimowicz and El Sherbiny [1975] used an inverted sugar solution of glucose, fructose and sucrose and Le Blanc et al. [2009] fed HFCS. Besides, both studies did not test concentrations higher than 750 ppm HMF and our test range covered concentrations up to 10.000 ppm HMF, which was legitimized by the results of our larval experiments.

Our comparison of toxicity of HMF to larvae and adults is hypothetical, not yet directly possible. Mass, consumption rate, composition of food and metabolism differ between these different development stages [Hrassnigg and Crailsheim, 2005]. Metabolism changes even in 
adult bees, depending on their age and stage of age polyethism [Haydak, 1970]. For example, duration of chronic intoxication is limited to a larval feeding period of 6 days and HMF intake was limited by the rigid applied amount of food close to natural conditions [Aupinel et. al, 2005], whereas adult bees consumed food and hence HMF ad libitum. They also received HMF within their food uninterrupted until day 22, which is a much longer period and higher overall exposition than immature stages, as pupae do not consume.

In our experiments we fed HMF in various concentrations solved in typically composed food to the two developmental stages [Barker and Lehner, 1978; Aupinel et al., 2005], what allowed us to compare larvae and adults via dose-response curves. From this we derive comparison of toxicity of HMF towards larvae and adults. Adults showed an extrapolated $\mathrm{LC}_{50}$ nearly 20 times higher than those of larvae on $\mathrm{d} 7$, whereas on $\mathrm{d} 22, \mathrm{LC}_{50}$ of larvae was 1.3 times higher than that of adult ones (Tab. II). This might be a result of the mentioned longer exposure to HMF and the higher consumed overall-dose of caged adult workers.

Previous comparison of toxicity on larvae and adult honey bees has been very limited. The Apenet Project [2009] in Italy delivered results on toxicity of two pesticides, fipronil and the neonicitinoid clothianidin, on both larvae and adults. Astonishingly larvae showed a much higher resistance after $24 \mathrm{~h}$ of acute intoxication than adult workers. As adults evinced a $\mathrm{LD}_{50}$ of about $4 \mathrm{ng}$ for both substances, larvae showed a $\mathrm{LD}_{50}$ of $39 \mathrm{ng}$ for fipronil and more than $3000 \mathrm{ng}$ for clothianidin. The fact that both substances act on the nervous system of insects and larvae present a comparatively simple nervous system might be the reason, why these substances are less toxic to larvae.

Beekeepers should notice the danger of HMF contamination and purchase their supplemental food from reliable sources or, when manufacturing sugar syrup by themselves, be careful not to produce or store under conditions that favour the building of HMF. Using not sold, possibly several years old honey as supplemental food might be noisome, especially regarding results like those of ALabdeen Makawi [2009], where long term stored honey can develop HMF-concentrations up to more than $900 \mathrm{ppm}$. When kept between $15-25^{\circ} \mathrm{C}$, honey stored for 28 months shows HMF concentrations below 60 ppm [Sancho et al., 1992].

Further research is needed to test more detailed concentrations ranging between 750 and 5000 ppm HMF to see when first significant differences in mortality occurs and hence determine a NOAEC (No Observed Adverse Effect Concentration) or LOAEC (Lowest Observed Adverse Effect Concentration), which should be found above 750 ppm HMF. Under natural conditions, honey stored within the hive will probably less likely develop a HMF concentration as high as the $\mathrm{LC}_{50}$ determined in our study. However, it is conceivable, that 
supplemental food, acid-catalyzed and long-term stored under improper conditions, might reach a HMF- level that can cause lethal or sublethal damage in a dimension that is not yet known. Indeed, the impact of sublethal HMF intoxication is needed to be investigated, as, especially in combination with other stressors, it might reduce resistance against environmental influences, pesticides, parasites and diseases. 


\section{References}

ALabdeen Makawi, S. Z.; Taha, M. I.; Zakaria, B. A.; Siddig, B.; Mahmod, H.; Elhussein, A. R. M,; Gad kariem, E. A. Identification and quantification of 5-Hydroxymethylfurfural HMF in some sugar-containing food products by HPLC. Pakistan Journal of Nutrition 2009, 8 (9), 1391-1396

APENET Report. Effects of coated maize seeds on honey bees. CRA API 2009, pp. 1-30 Aupinel, P.; Fortini, D.; Dufour, H.; Tasei, J.N.; Michaud, B.; Odoux, J. F.; Pham-Delègue, M.H. Improvement of artificial feeding in a standard in vitro method for rearing Apis mellifera larvae. Bulletin of Insectology 2005, 58 (2), 107-111

Aupinel, P.; Fortini, D.; Dufour, H.; Michaud, B.; Marolleau, F.; Tasei, J.N.; Odoux, J. F. Toxicity of dimethoate and fenoxycarb to honey bee brood (Apis mellifera), using a new in vitro standardized feeding method. Pest Management Science 2007, 63, 1090-1094

Bailey, L. The effect of acid-hydrolysed sucrose on honeybees. Journal of Apicultural Research 1966, 5(3), 127-136

Barker, R.J.; Lehner, Y. Galactose, a sugar toxic to honey bees, found in exudate of tulip flowers. Apidologie 1976, 7 (2), 109-112

Barker, R.J. Some carbohydrates found in pollen and pollen substitutes are toxic to honey bees. Journal of Nutrition 1977, 107, 1859-1862

Barker, R. J.; Lehner, Y. Laboratory comparison of high fructose corn syrup, grape syrup, honey, and sucrose syrup as maintenance food for caged bees. Apidologie 1978, 9(2), $111-116$

Bogdanov S. Harmonised methods of the International honey commission. International honey commission 2002, pp. 1-62

Bogdanov, S.; et al. Honey Quality and International Regulatory Standards-Review by the International Honey Commission. Bee world 1999

Brodschneider, R.; Riessberger-Gallé, U.; Crailsheim, K. Flight performance of artificially reared honeybees (Apis mellifera). Apidologie 2009, 40, 441-449

Brodschneider, R.; Crailsheim, K. Nutrition and Health in honey bees. Apidologie 2010, 41, 278-294

Brodschneider, R.; Moosbeckhofer, R.; Crailsheim, K. Surveys as a tool to record winter losses of honey bee colonies: a two year case study in Austria and Southern Tyrol. Journal of Apicultural Research 2010, 49 (1), 23-30

Brouwers, E. V. M.; Ebert, R.; Beetsma, J. Behavioural and physiological aspects of nurse 
bees in relation to the composition of larval food during caste differentiation in the honeybee. Journal of Apicultural Research 1987, 26(1), 11-23

COUNCIL DIRECTIVE 2001/110/EC of 20 December 2001 relating to honey. Official Journal of the European Communities 2002, L10/47-52

Doner, L.W. The sugars of honey. Journal of the Science of Food and Agriculture 1977, 28, 443-456

Evans, J.D.; Chen Y. P.; Di Prisco, G.; Pettis, J.; Williams, V. Bee cups: single-use cages for honey bee experiments. Journal of Apicultural Research and BeeWorld 2009, 48(4), 300-302

Haydak, M. H. Honey Bee Nutrition. Annual Review of Entomology 1970, 15, 143-156

Hendriksma, H. P.; Härtel, S.; Steffan-Dewenter, Ingolf. Honey bee risk management: new approaches for in vitro larvae rearing and data analyses. Methods in Ecology and Evolution 2011, 2, 509-519

Hrassnigg, N.; Crailsheim, K. Differences in drone and worker physiology in honeybees (Apis mellifera) Apidologie 2005, 36, 255-277

Jachimowicz, T.; El Sherbiny, G. Zur Problematik der Verwendung von Invertzucker für die Bienenfütterung. Apidologie 1975, 6 (2), 121-143

Jeuring,H. J.; Kuppers, F. J. E. M. High performance liquid chromatography of furfural and hydroxymethylfurfural in spirits and honey. Journal of the Association of Official Analytical Chemists 1980, 63(6), 1215-1218

Karabournioti, S.; Zervalaki, P. The effect of heating on honey HMF and invertase. Apiacta 2001, 36 (4), 177-181

Kim, H.; Richardson, M. Determination of 5-hydroxymethyfurfural by ion-exclusion chromatography with UV-detection. Journal of Chromatography 1992, 593, 153-156

Kunert, K.; Crailsheim, K. Sugar and protein in the food for honeybee worker larvae. Chemistry and biology of social insects. 1987, 164-165

LeBlanc, B. W.; Eggleston, G.; Sammataro, D.; Cornett, C.; Dufault, R.; Deeby, T.; Cyr, E. S. Formation of Hydroxymethylfurfural in domestic high- fructose corn syrup and its toxicity to the honey bee (Apis mellifera). Journal of Agricultural and Food Chemistry 2009 57(16), 7369-7376

Medrzycki, P.; Sgolastra, F.; Bortolotti, L,: Bogo, G.; Tosi, S.; Padovani, E.; Porrini, C.; Sabatini, A. G. Influence of brood rearing temperature on honey bee development and susceptibility to poisoning by pesticides. Journal of Apicultural Research 2010, 49(1), 52-59 OEPP/EPPO. EPPO standards PP1/170 (3). Test methods for evaluating the side effects of 
plant protection products on honeybees. Bulletin OEPP/EPPO Bulletin 2001, 31, 323-330

OEPP/EPPO. Environmental risk assessment scheme for plant protection products. Bulletin OEPP/EPPO Bulletin 2003, 33, 141-145

Oomen, P. A.; De Ruijter, A.; Van der Steen, J.; Method for honeybee brood feeding tests with insect growth-regulating insecticides. Bulletin OEPP/EPPO Bulletin 1992, 22, 613614

Peng, Y.S.C.; Mussen, E.; Fong, A.; Montague, M. A.; Tyler, T. Effects of chlortetracycline of honey bee worker larvae reared in vitro. Journal of Invertebrate Pathology. 1992, 60, $127-133$

Rembold, H.; Lackner, B. Rearing of honeybee larvae in vitro: effect of yeast extract on queen differentiation. Journal of Apicultural Research 1981, 20(3), 165-171

Risner, C.H.; Kiser, M. J.; Dube, M.F. An aqueous high-performance liquid chromatographic procedure for the determination of 5-Hydroxymethylfurfural in honey and other sugar-containing materials. Journal of Food Science 2006, 71(3), 179-184

Ruiz-Matute, A. I.; Weiss, M.; Sammataro, D.; Finely, J.; Sanz, M. L. Carbohydrate composition of high-fructose corn syrups (HFCS) used for bee feeding: Effect on honey composition. Journal of Agricultural and Food Chemistry 2010, 58, 7317-7322

Sabatini, A. G.; Marcazzan, G. L.; Caboni, M. F.; Bogdanov, S.; De Almeida-Muradian, L. B. Quality and standardisation of Royal Jelly. Journal of ApiProduct and ApiMedical Science 2009, 1(1), 16-21

Sancho, M. T.; Muniategui, S.; Huidobro, J. F.; Lozano, J. S. Aging of Honey. Journal of Agricultural and Food Chemistry 1992, 40, 134-138

Vandenberg, J. D.; Shimanuki, H. Technique for rearing worker honeybees in the laboratory. Journal of Apicultural research 1987, 26(2), 90-97

Tosi, E.; Ciappini, M. C.; Ré, E.; Lucero, H. Honey thermal treatment effects on hydroxymethylfurfural content. Food chemistry 2001, 77, 71-74

Van der Zee, R.; Pisa, L. Bijensterfte 2009-10 en toxische invertsuikersiroop. NCB Rapport 02/2010

White, J. W. Methods for determining Carbohydrates, Hydroxymethylfurfural, and Proline in honey: collaborative study. Journal of the Assiciation of Official analytical Chemists 1979, 62(3), 515-526

White, J. W. The role of HMF and diastase assays in honey quality evaluation. Bee World 1994, 75(3), 104-117 
Winkler, O. Beitrag zum Nachweis und zur Bestimmung von Oxymethylfurfurol in Honig und Kunsthonig. Zeitschrift für Lebensmittel-Untersuchung und-Forschung 1955, 102(3) 161-167 